\title{
Abiraterone Regimen
}

National Cancer Institute

\section{Source}

National Cancer Institute. Abiraterone Regimen. NCI Thesaurus. Code C160794.

A regimen consisting of abiraterone acetate that may be used in the treatment of metastatic prostate cancer. 